\title{
Large bilateral foveal cysts in the inner retina of a patient treated with tamoxifen, diagnosed with Fourier-domain optical coherence tomography
}

This article was published in the following Dove Press journal:

Clinical Ophthalmology

9 April 2013

Number of times this article has been viewed

Ilias Georgalas

Theodore Paraskevopoulos

Dimitris Papaconstaninou

Dimitiris Brouzas

Chryssanthi Koutsandrea

Department of Ophthalmology,

"G Gennimatas" Hospital

of Athens, NHS, University

of Athens, Athens, Greece
Correspondence: Ilias Georgalas Department of Ophthalmology, "G Gennimatas" Hospital of Athens, NHS, University of Athens, 59 Chrysanthemon Street. 15452 Athens, Greece Tel/fax +30 2l 0776800 Email igeorgalas@yahoo.com
Purpose: To report a case of a patient receiving tamoxifen with visual deterioration and describe the unusual optical coherence tomography (OCT) findings.

Method: Observational case report.

Results: A 55-year-old female patient was referred to our department complaining of gradual visual deterioration in both eyes. Medical history was unremarkable apart from breast cancer for which she had received tamoxifen for 10 years (mean dosage $20 \mathrm{mg}$ /day). Best corrected visual acuity was 20/400 in her right eye and 20/40 in her left eye. Fundoscopy in both eyes was without any obvious signs of maculopathy. However, Fourier-domain OCT demonstrated bilateral extensive areas of disruption in inner retinal layers without any signs of crystalline retinopathy. Six months after the cessation of tamoxifen, the situation remains unchanged.

Conclusion: Patients receiving tamoxifen should be monitored with high-resolution OCT for fundoscopically invisible changes in the inner retinal layers, the progression of which may seriously affect the patient's vision and subsequently their quality of life.

Keywords: maculopathy, OCT

\section{Introduction}

Optical coherence tomography (OCT) is an interferometric imaging technique which produces cross-sectional images of the retina and in recent years has been widely used in the study of macular diseases. ${ }^{1,2}$ Tamoxifen is a nonsteroidal antiestrogen, which belongs to the family of selective estrogen receptor (ER) modulators, drugs that have the ability to occupy ERs, acting as ER antagonists in breast tissue. As a result, tamoxifen is widely used as adjuvant endocrine therapy for women with hormoneresponsive breast cancer. ${ }^{3}$

Incidence of ocular toxicity among patients receiving tamoxifen is rare $(0.6 \%)$; cataract, vortex keratopathy, optic neuritis and retinopathy are the most common manifestations. ${ }^{3-5}$

We report, herein, a case of a 55-year-old woman who presented with bilateral, severe visual deterioration after treatment with tamoxifen and describe the Fourier-domain OCT findings.

\section{Case report}

A 55-year-old female patient was referred to our department complaining of gradual visual deterioration in both eyes. She had been seen by her local optician and ophthalmologist who had failed to explain the reduction in her vision. Medical history was unremarkable apart from breast cancer, diagnosed in 2002, for which she received 
tamoxifen for 10 years (mean dosage $20 \mathrm{mg}$ /day), which was withdrawn only 15 days prior to her visit. The reason for the prolonged reception of tamoxifen is not known, since her oncological medical record was not available. The patient's best corrected visual acuity at presentation was 20/400 in her right eye and 20/40 in her left eye. Intraocular pressure was 17 and $13 \mathrm{mmHg}$ in her right and left eye, respectively. Examination of the anterior segment was unremarkable. Fundoscopy in both eyes was without any obvious signs of maculopathy (Figure 1). Posterior vitreous was attached to the retina in both eyes. Fourier-domain OCT was used for examination of the fovea; it demonstrated bilateral extensive areas of disruption in inner retinal layers (Figure 2A and B). The OCT type that was used for the diagnosis was RTVue model RT-100 by Optovue (Fremont, CA, USA). Through the OCT, the dimensions of the foveal cystoid spaces were measured and found to be $78 \mu \mathrm{m} \times 823 \mu \mathrm{m}$ in the right eye and $74 \mu \mathrm{m} \times 607 \mu \mathrm{m}$ in the left eye. Measurement was achieved by using the manual program of the instrument. Fluorescein angiography did not show any leakage and excluded the diagnosis of type 2 retinal telangiectasia. Six months after the cessation of tamoxifen, the situation remains unchanged.

\section{Discussion}

OCT is an interferometric imaging technique which produces cross-sectional images by mapping the depth-wise reflections of low-coherence laser light from tissue. Fourier- or spectraldomain OCT refers to Fourier transformation of the optical spectrum of the low-coherence interferometer. Imaging of multilayer objects, such as retina, results in various modulation periodicities representing the depth of each layer, with amplitude of the spectrum modulation proportional to the reflectivity of the layer. The greatest advantage of spectral-domain OCT, over conventional time-domain OCT is the increase in scan speed. With the spectral-domain OCT, imaging with 25,000-100,000 axial scans per second is routinely possible. This is more than 100 times faster than the time-domain technique., ${ }^{1,2}$

Tamoxifen is a nonsteroidal antiestrogen, which belongs to the family of selective ER modulators, drugs that have the ability to occupy ERs (ER $\alpha$ and ER $\beta$ ), acting as ER antagonists in breast tissue. As a result, tamoxifen is widely used as adjuvant endocrine therapy for women with breast cancer. ER $\alpha$ and ER $\beta$ are also present within the neural retina and the pigment epithelium of men and women, where tamoxifen is reported to decrease glutamate uptake. ${ }^{3}$

Incidence of ocular toxicity among patients receiving tamoxifen is rare, approximately $0.6 \%$. Ocular manifestations of tamoxifen include tamoxifen retinopathy, corneal epithelial deposits which can lead to vortex keratopathies, induction of posterior subcapsular cataract, and clinically evident optic neuritis.

Tamoxifen retinopathy is typically characterized by the presence of small refractile deposits in the nerve fiber and inner plexiform layers, primarily in the perifoveal area. Refractile deposits do not cause significant visual impairment; histopathologically, they are suggested to represent axonal degeneration, mainly in the nerve fiber layer in the parafoveal region. Due to tamoxifen's amphiphilic nature, it is suggested that it binds to polar lipids, accumulates in lysosomes, and causes cell oxidative damage. ${ }^{4-7}$ Numerous researchers have suggested that tamoxifen retinopathy is not caused by actions of tamoxifen on ERs, but stems instead from tamoxifen's cationic amphiphilic properties, which resemble those of chloroquine. ${ }^{3}$

All cases of tamoxifen maculopathy studied with spectraldomain OCT in the literature include crystalline maculopathy

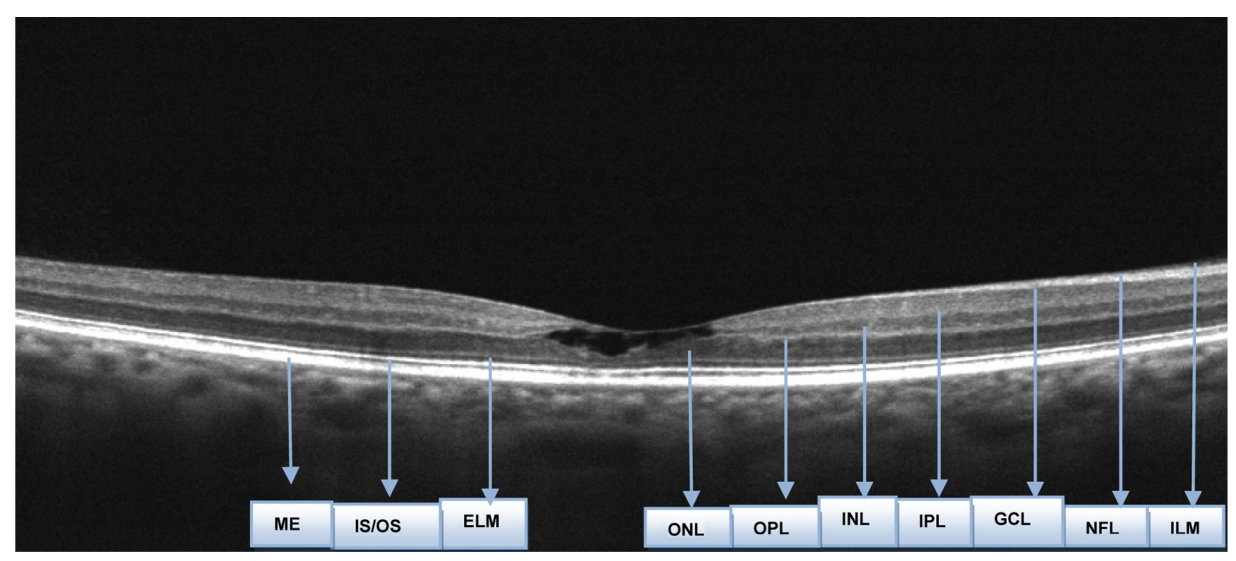

Figure I Optical Coherence Tomography of the right eye.

Abbreviations: ELM, External Limiting Membrane; GCL, Ganglion Cell Membrane; ILM, Internal Limiting Membrane; INL, Inner Nuclear Layer; IPL, Inner Plexiform Layer; IS/OS, Inner-Outer Segment Photoreceptors; NFL, Nerve Fiber Layer; OPL, Outer Plexiform Layer; ONL, Outer Nuclear Layer; PE, Retinal Pigment Epithelium. 


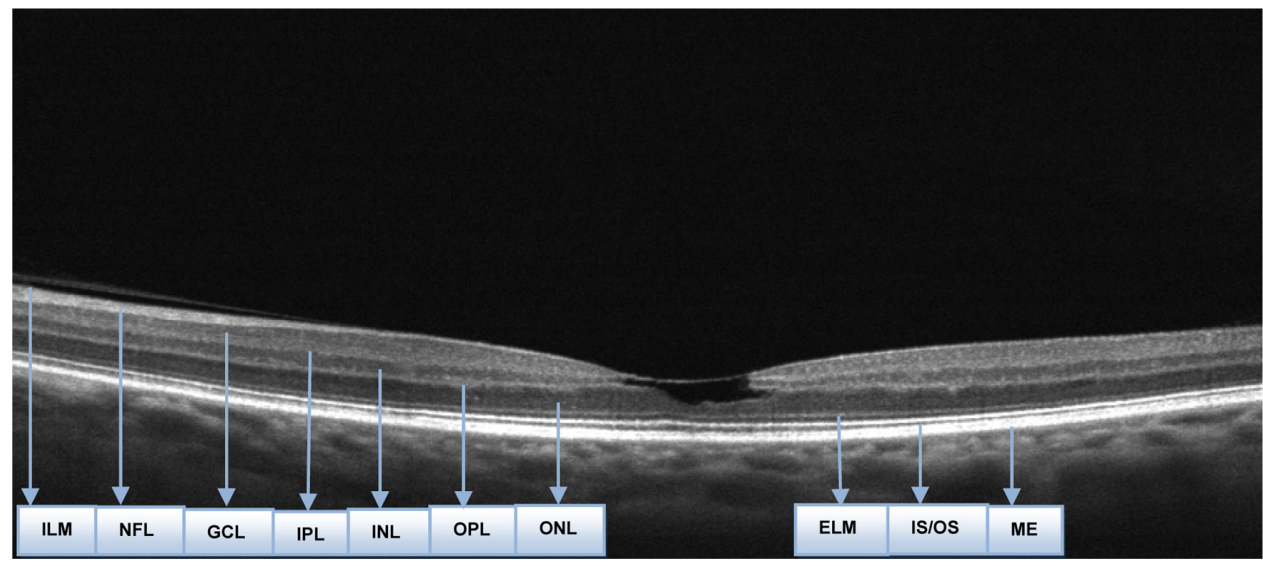

Figure 2 Optical Coherence Tomography of the left eye.

Abbreviations: ELM, External Limiting Membrane; GCL, Ganglion Cell Membrane; ILM, Internal Limiting Membrane; INL, Inner Nuclear Layer; IPL, Inner Plexiform Layer; IS/OS, Inner-Outer Segment Photoreceptors; NFL, Nerve Fiber Layer; OPL, Outer Plexiform Layer; ONL, Outer Nuclear Layer; PE, Retinal Pigment Epithelium.

with refractile deposits, accompanied by unilateral foveal cysts of small size. ${ }^{7-10}$ In all cases, the described lesions consisted of hyperreflective substances in combination with outer retinal atrophy, photoreceptor disruption, and defects in the outer retinal layers which caused the decrease in the visual acuity of the patients. In our case, interestingly, the retinal damage concerned only the inner layers, without any refractile deposits or outer retinal defects, giving the impression of a pseudohole from which tamoxifen maculopathy can be differentiated by the absence of posterior vitreous detachment and the normal foveal contour. The absence of refractile deposits, posterior vitreous detachment, and outer retinal defects was responsible for the almost "normal appearance" of the macula in the fundoscopy. However, the permanent bilateral reduction in the vision of our patient associated only with subtle fundoscopic changes emphasizes the role of early detection of inner foveal damage with high-resolution OCT. Patients receiving tamoxifen should be monitored with high-resolution OCT for fundoscopically invisible changes in the inner retinal layers, the progression of which may seriously affect a patient's vision and subsequently their quality of life.

\section{Disclosure}

The authors report no conflicts of interest. The authors alone are responsible for the content and writing of the paper.

\section{References}

1. Kiernan DF, Mieler WF, Hariprasad SM. Spectral-domain optical coherence tomography: a comparison of modern high-resolution retinal imaging systems. Am J Ophthalmol. 2010;149(1):18-31.

2. Wolf S, Wolf-Schnurrbusch U. Spectral-domain optical coherence tomography use in macular diseases: a review. Ophthalmologica. 2010;224(6):333-340.

3. Eisner A, Luoh SW. Breast cancer medications and vision: effects of treatments for early-stage disease. Curr Eye Res. 2011;36(10):867-885.

4. Hager T, Hoffmann S, Seitz B. Unusual symptoms for tamoxifenassociated maculopathy. Ophthalmologe. 2010;107(8):750-752. German.

5. Srikantia N, Mukesh S, Krishnaswamy M. Crystalline maculopathy: a rare complication of tamoxifen therapy. $J$ Cancer Res Ther. 2010; 6(3):313-315.

6. Chung H, Kim D, Ahn SH, et al. Early detection of tamoxifen-induced maculopathy in patients with low cumulative doses of tamoxifen. Ophthalmic Surg Lasers Imaging. 2010;9:1-5. Epub March 9, 2010.

7. Toler SM. Oxidative stress plays an important role in the pathogenesis of drug-induced retinopathy. Exp Biol Med (Maywood). 2004;229(7): 607-615.

8. Mauget-Faÿsse M, Gambrelle J, Quaranta-El, Maftouhi M. Optical coherence tomography in tamoxifen retinopathy. Breast Cancer Res Treat. 2006;99(1):117-118.

9. Gianni L, Panzini I, Li S, et al; International Breast Cancer Study Group (IBCSG). Ocular toxicity during adjuvant chemoendocrine therapy for early breast cancer: results from International Breast Cancer Study Group trials. Cancer. 2006;106(3):505-513.

10. Gualino V, Cohen SY, Delyfer MN, Sahel JA, Gaudric A. Optical coherence tomography findings in tamoxifen retinopathy. Am J Ophthalmol. 2005;140(4):757-758.
Clinical Ophthalmology

\section{Publish your work in this journal}

Clinical Ophthalmology is an international, peer-reviewed journal covering all subspecialties within ophthalmology. Key topics include: Optometry; Visual science; Pharmacology and drug therapy in eye diseases; Basic Sciences; Primary and Secondary eye care; Patien Safety and Quality of Care Improvements. This journal is indexed on
PubMed Central and CAS, and is the official journal of The Society of Clinical Ophthalmology (SCO). The manuscript management system is completely online and includes a very quick and fair peer-review system, which is all easy to use. Visit http://www.dovepress.com/ testimonials.php to read real quotes from published authors. 